
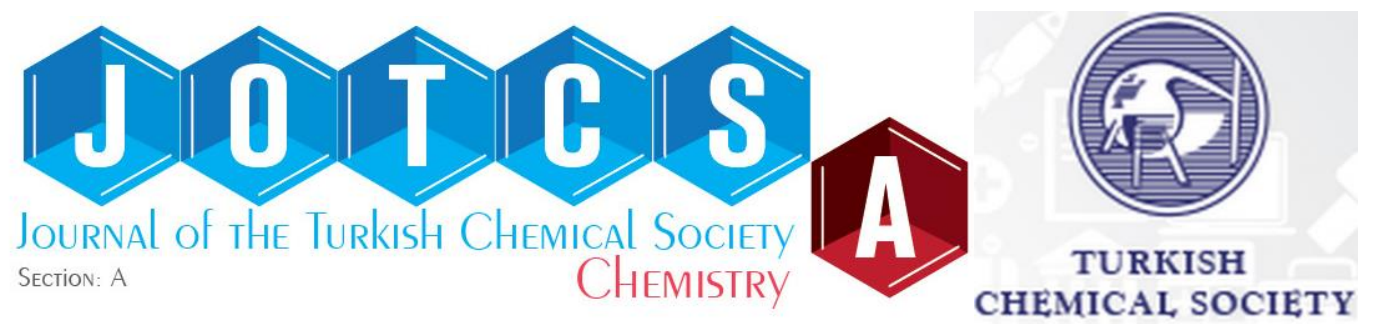

\title{
Investigation of Organic Solvents' Effects on Kenaf (Hibiscus cannabinus L.) Biomass Conversion in Subcritical Water
}

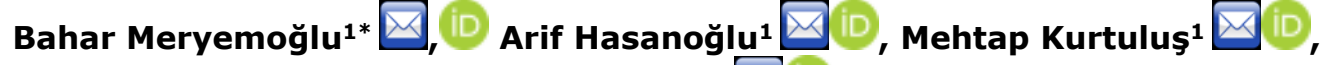 \\ Sibel Irmak 2 D \\ ${ }^{1}$ Department of Chemistry, Çukurova University, 01330, Adana, Turkey \\ 2 Department of Biological Systems Engineering, University of Nebraska-Lincoln, Lincoln, NE 68583, USA
}

Abstract: Kenaf biomass was hydrolyzed under subcritical water conditions in the presence of various organic solvents. The solvents tested were tetrahydrofuran (THF), acetone, xylene (mixed isomers) and methanol. The organic compounds released into hydrolysates, total organic contents, water-soluble total phenols, and the molecular weight distributions of the polysaccharides in the hydrolysates, solid residues leftover after hydrolysis and gaseous products formed during the solubilization process were determined. The results showed that organic solvents significantly enhanced the dissolution of kenaf biomass (methanol $<$ (omp)xylene $\leq$ acetone $\sim$ tetrahydrofuran). The hydrolysis percentage was found to be between $75-82 \%$ depending on the type of the solvent. Hydrolysis yield and total organic carbons released into hydrolysates highly differed when the solubilization process was performed under carbon dioxide pressure and this effect considerably varied based on the type of solvent used in hydrolysis process. The main gas product formed during hydrolysis process was carbon dioxide with $\sim 80 \%$ composition. Morphological measurements of the solid biomass residues left after hydrolysis showed substantial degradations with increasing number of pores on the biomass surfaces.

Keywords: Biomass, Kenaf, Organic Solvent, Hydrolysis, Subcritical water.

Submitted: May 25, 2018. Accepted: December 27, 2018.

Cite this: Meryemoğlu B, Hasanoğlu A, Kurtuluş M, Irmak S. Investigation of Organic Solvents' Effects on Kenaf (Hibiscus cannabinus L.) Biomass Conversion in Subcritical Water. JOTCSA. 2018;5(3):1423-30.

DOI: http://dx.doi.org/10.18596/jotcsa.427258.

*Corresponding author. E-mail: meryemoglubahar@gmail.com.

\section{INTRODUCTION}

The need for energy has been increasing continuously as a result of the rapid increase of the world's population. There is growing interest worldwide in the utilization of renewable sources for fuels, materials, and chemicals due to the depletion of fossil resources and environmentally non-friendly nature of the synthetic products. Lignocellulosic biomass can substitute for fossil resources in the production of a wide range of value-added products such as biofuels, bioproducts, and chemicals. Lignocellulosic biomass materials are abundant, cheap, and renewable resources and their non-edible alternatives are particularly important since they do not compete with the food related raw materials in conversion into useful products (1).
The complex and rigid structures of lignocellulosic biomass require an effective pretreatment before breaking down into soluble components with the processes of hydrolysis. The methods of pretreatment can be physical, physicochemical, chemical, or biological (2). Extent of lignin and hemicellulose removals, reduction in cellulose crystallinity, and increasing the porosity of the biomass structure depend on the pretreatment method applied (1). Subcritical water is a liquid under pressure and in the temperature range of $100-374^{\circ} \mathrm{C}$. This liquid usually is used in the extraction of plants. The optimal conditions are determined by changing the pressure and temperatures to obtain the maximum efficiency of the material to be extracted. Significant changes occur in the physical and chemical properties of the water, especially in the dielectric constant $(\varepsilon)$ under high pressure and 
temperature. The extraction efficiency was equivalent to the supercritical fluid or solvent extraction yield even without reaching the critical temperature point. The extraction with subcritical water began as an alternative to supercritical fluid extraction and solvent extraction. There are many advantages to using subcritical water. Some of these are environmental friendly, inexpensive, easy to find, non-toxic, and produces no organic waste at all. Subcritical water hydrolysis is an alternative pretreatment method to break down lignocellulosic biomass by operating process temperature and pressure conditions. This method is totally environmentally friendly and uses water in as reaction medium. The maximum solubilization yields of biomass materials with this method were found to be $70-75 \%$ at $250{ }^{\circ} \mathrm{C}$ $(3,4)$. Organic solvents play an important role in enhancing yields of the process in many applications. Several studies for biomass conversion were performed with this method using various organic solvents in the reaction medium (5-11). For this purpose, the present study was designed to solubilize lignocellulosic biomass in subcritical water by addition of nonpolar (omp-xylene), aprotic polar (tetrahydrofuran, acetone) and polar protic (methanol) solvents into reaction medium. Thus, the partial solubility of lignin will be improved in this study.

\section{EXPERIMENTAL SECTION}

\section{Hydrolysis of Kenaf biomass}

Kenaf biomass (Hibiscus cannabinus L.) was hydrolyzed under subcritical water condition. The amount of $10 \mathrm{~g}$ of kenaf and $350 \mathrm{~mL}$ of water were placed into a $500 \mathrm{~mL}$ stainless steel high pressure reactor (Parr Model 4575 HP/HT, Parr Instrument Co., Moline, IL, USA). Then, the reactor was heated until $250{ }^{\circ} \mathrm{C}$ and pressurized with/without $\mathrm{CO}_{2}$ using ISCO 260D pump (Isco Inc., Lincoln, Nebraska, USA) to $27.58 \mathrm{MPa}$ for 2 h. After $2 \mathrm{~h}$, the reactor was cooled up at room temperature within the reactor. The experiments with organic solvents were performed by addition of $3 \%$ of THF, acetone, xylene or methanol into reactor. After experiment, kenaf hydrolysate and solid residue were collected for analysis. The solid residue were dried at $100{ }^{\circ} \mathrm{C}$ in order to determine the percentage of hydrolysis. The experiments were performed in duplicate.

\section{Analysis}

The solid residues leftover after hydrolysis were characterized by FTIR using ATR (Perkin Elmer Spectrum RX-I FTIR System) and SEM analysis (ZEISS SUPRA 55). The hydrolysates were analyzed by TOC (total organic carbon analyzer), UV-VIS, GC-MS, and HPLC. Total organic carbon content was determined using Tekmar Dohrmann Apollo 9000 instrument.

The compositions of volatile organic compounds in the hydrolysates were determined by a Thermo Finnigan Trace Gas Chromatograph and Mass
Spectrometer (GC-MS) using Thermo TR-5 MS capillary column $(60 \mathrm{~m} \times 0.25 \mathrm{~mm}$ ID $\times 0.25 \mathrm{~mm}$ film thickness). For this analysis, $50 \mathrm{~mL}$ of kenaf hydrolysate was extracted with diethyl ether and dried through a $\mathrm{Na}_{2} \mathrm{SO}_{4}$ column. Diethylether was removed by using a rotary evaporator. The oven temperature of the GC-MS system was as follows: holding at $40{ }^{\circ} \mathrm{C}$ for $5 \mathrm{~min}$; increasing the temperature from $40{ }^{\circ} \mathrm{C}$ to $280{ }^{\circ} \mathrm{C}$ with 2.5 ${ }^{\circ} \mathrm{C} / \mathrm{min}$ heating rate and holding at this temperature for $10 \mathrm{~min}$. Inlet temperature was $240{ }^{\circ} \mathrm{C}$. The $70 \mathrm{eV}$ and $240{ }^{\circ} \mathrm{C}$ were set as ionization voltage and ion source temperature, respectively. The $1 \mu \mathrm{L}$ of sample was injected in splitless mode. Solvent delay was $6 \mathrm{~min}$. The NIST 2002 mass spectral library was used in identification.

The molecular weight distributions of the polysaccharides in the hydrolysates were determined by gel permeation chromatography (GPC) using 4400, 9900, 21,400, 43,500, $124,000,196,000,277,000$ and 401,000 Da dextran standards. The hydrolysates were filtered through $0.22 \mu \mathrm{m}$ syringe filter before analysis. GPC analysis was performed by an LC-6AD Shimadzu high performance liquid chromatograph equipped with SIL-10AF Shimadzu auto injector (Shimadzu, Kyoto, Japan) and Shimadzu RID-10A refractive index detector (RID).

Total water-soluble phenolics contents of the hydrolysates were determined by FolinCiocalteau assay (12). Absorbance at $765 \mathrm{~nm}$ was recorded using a spectrophotometer (Thermo Scientific Genesys 10S UV/Vis).

\section{RESULTS AND DISCUSSION}

\section{Hydrolysis yields of kenaf biomass under different water-organic solvents mixture} Kenaf samples were subjected to omp-xylene (non-polar), THF (aprotic polar), acetone (aprotic polar) and methanol (polar protic) solvents under subcritical water condition under pressure of carbon dioxide. It is known that polar aprotic solvents are good solvents for lignin solubilization.

Some experiments were performed to examine the effect of the amount of solvent on the percentage hydrolysis and product distribution using THF. The $1 \%, 3 \%$ and $5 \%$ of THF were used. The percentage hydrolysis was increased with increasing THF amount from $1 \%(75,1 \pm 4,4)$ to $3 \%(82,5 \pm 3,6)$. When the $\% 5$ of THF was used, it was seen that the percentage hydrolysis was decreased $(78,8 \pm 2,7)$. Similarly, the phenolics concentrations of hydrolysates were also affected by the amount of THF. According to results, the phenolics concentrations of hydrolysates increased in following order 2021,9 $<2832,1<3213,1 \mathrm{ppm}$ for $\% 1, \% 5$ and $\% 3$ of THF respectively. It was decided that $\% 3$ organic solvent was more suitable because of the highest 
percentage hydrolysis and phenolic contents, less gas formation in the hydrolysis process, more polysaccharide.

The percentage hydrolysis and total organic carbon (TOC) values obtained after these treatments were presented in Figure 1. As given in Figure 1, the percentage hydrolysis increased in the following order; methanol < omp-xylene $\leq$ acetone $\sim$ tetrahydrofuran. The hydrolysis with non-polar and aprotic polar solvents was observed to be better compared to one performed with a polar protic solvent. Previous studies about solubility of lignin in the mixtures of waterorganic solvents showed that our results are in harmony (13-16). The organic solvents are known to affect reaction rate, reaction mechanism, and yield and product distributions in many reaction systems. The changes in dipole moment and the hydrogen bonds between solvent and solute (biomass) can significantly change dissolution process, thermodynamic state of the reactants, activation energy of the products, and compositions of the reaction mixture (17). It was observed that yield of hydrolysis and TOC released highly differed when the solubilization process was performed under carbon dioxide pressure and this effect considerably varied as based on the type of solvent used in hydrolysis process (Figure 1). The maximum TOC released was observed when THF solvent was used in solubilization media.

During hydrolysis process, gasification reactions can also take place. It is preferable to be gasification less but dissolution more. To determine solvent effect correctly, amount of gas formed during hydrolysis must be determined along with hydrolysis percentage and total organic carbon contents of the hydrolysates. The amount of gas mixtures formed during hydrolysis were determined by GC using TCD detector and presented in Table 1 . The amount of the gas was $745 \mathrm{~mL}$ when acetone was used in hydrolysis in the absence of carbon dioxide pressure. The gas amounts in other solvents were ranged between 525 and $630 \mathrm{~mL}$.

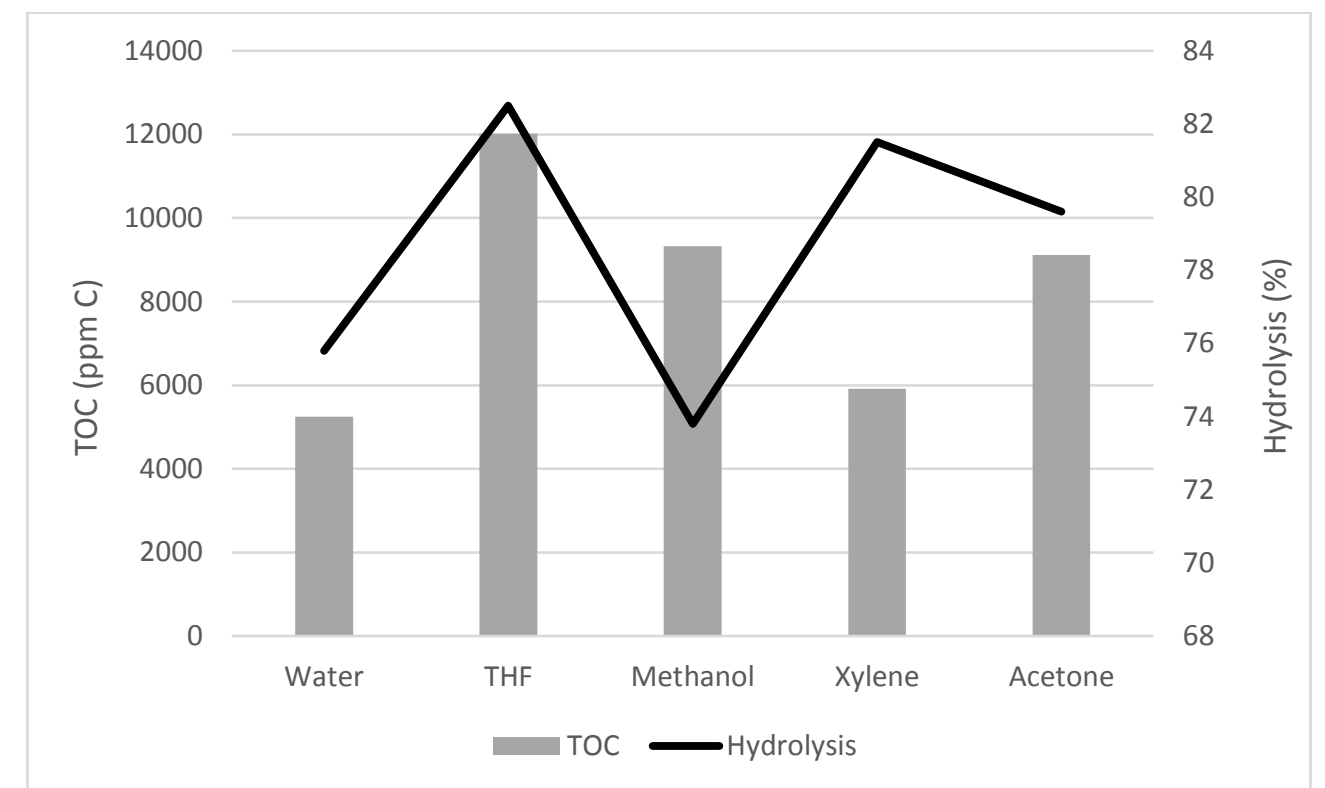

Figure 1. The percentage hydrolysis and TOC yield of kenaf biomass with different water-organic solvent mixture.

The main product in the gas mixtures was found to be carbon dioxide (78-83\%) that followed by carbon monoxide (14-19\%) (Table 1). Hydrogen composition was between $2.1-2.8 \%$ in all hydrolysis experiments. The gas mixtures contained trace amount of methane (0.2\%).

Table 1. The gas composition of kenaf biomass with different water-organic solvent mixture $\left(\mathrm{CO}_{2}\right.$ pressure was not applied).

\begin{tabular}{lccccc}
\hline Solvents & \multirow{2}{*}{$\begin{array}{c}\text { Gas } \\
\text { Volume }\end{array}$} & \multicolumn{4}{c}{ Gas composition (\%) } \\
\cline { 4 - 6 } & $(\mathbf{m L})$ & $\mathbf{H}_{\mathbf{2}}$ & $\mathbf{C H}_{\mathbf{4}}$ & $\mathbf{C O}_{\mathbf{2}}$ & $\mathbf{C O}$ \\
\hline Water & $630 \pm 30$ & $2.3 \pm 0.8$ & $0.2 \pm 0.1$ & $78.5 \pm 1.1$ & $19.0 \pm 1.1$ \\
\hline Water+ 3 \% THF & $525 \pm 35$ & $2.5 \pm 0.1$ & $0.2 \pm 0.0$ & $80.6 \pm 0.5$ & $16.7 \pm 0.8$ \\
\hline Water+ 3 \% Methanol & $650 \pm 30$ & $2.8 \pm 0.2$ & $0.3 \pm 0.1$ & $80.9 \pm 0.4$ & $16.0 \pm 0.6$ \\
\hline Water+3 \% Acetone & $745 \pm 15$ & $2.7 \pm 0.3$ & $0.3 \pm 0.1$ & $82.7 \pm 1.2$ & $14.3 \pm 0.4$ \\
\hline Water+ 3 \% Omp-Xylene & $670 \pm 20$ & $2.1 \pm 0.3$ & $0.2 \pm 0.1$ & $81.0 \pm 2.1$ & $16.7 \pm 0.9$ \\
\hline
\end{tabular}


Based on these results, we can conclude that THF is the best organic solvent for hydrolysis process resulting the highest hydrolysis percentage $(82.5 \%)$ and TOC (> 10,500 ppm) values by producing the least gas volume $(525 \mathrm{~mL})$.

\section{Products}

The products in the hydrolysates were characterized by GC-MS, UV-Vis and GPC analytical techniques. Table 2 shows the compounds formed after hydrolysis of kenaf biomass in different water-organic solvent mixtures. Carbon dioxide was used as a pressurizing gas in the hydrolysis process. Differences in the viscosity, the dielectric constant, polarity of the solvents $(18,19)$ affected the solubilization of biomass.

In many studies, lignocellulosic material was treated with organic solvents and as a result of this treatment, most of lignin was removed (2022). And also, higher hemicellulose conversion was obtained with use of organic solvent such as dimethylformamide (DMF) in the processes (23).
Although these studies were conducted, the comparison of organic solvents on kenaf subcritical water hydrolysis has not been reported yet. The use of organic solvents in hydrolysis partially hydrolyzes the lignin bonds and lignincarbohydrate bonds, and solid residues leftover after hydrolysis mainly consists of cellulose and hemicellulose. In this study, the organic solvent removes the lignin from the lignocellulosic material but most of the hemicellulose sugars are also dissolved in this process. Because of that the compounds were mainly phenolics which were released from lignin fraction of biomass. Watersoluble phenolic composition of the hydrolysates varies depending on the solvent used in experiments (Table 3). The phenolics concentrations were highest in water-xylene mixture. The total phenolics in this solvent mixture were found to be $3601.1 \mathrm{mg} / \mathrm{L}$. On the other hand, water-THF mixture yielded the lowest phenolics in the hydrolysis (Table 3). From our work, it was found that the use of organic solvents in hydrolysis process provided enhancing the product distrubiton as well as hydrolysis yield.

Table 2. GC-MS analysis of kenaf hydrolysates in different water- organic solvent mixtures

\begin{tabular}{|c|c|c|}
\hline $\begin{array}{l}\text { Retention time } \\
\text { (min) }\end{array}$ & Compound Name & $\begin{array}{l}\text { MS fragments used in } \\
\text { identification }(\mathrm{m} / \mathrm{z})\end{array}$ \\
\hline 15.69 & Furfural & $96\left(\mathrm{M}^{+}\right), 95,68,67,51$ \\
\hline 18.7 & $\begin{array}{c}\text { Corylon (2-hydroxy-3-methyl-2-cyclopenten- } \\
\text { 1-one) }\end{array}$ & $112\left(\mathrm{M}^{+}\right), 97,83,41,27$ \\
\hline 22.3 & 2-methoxyphenol & $124\left(\mathrm{M}^{+}\right), 109,95,81,53$ \\
\hline 28.06 & 3-methyl-1,2-cyclopentadione & $112\left(\mathrm{M}^{+}\right), 97,83,69,55$ \\
\hline 31.23 & 4-methyl phenol & $110,108\left(\mathrm{M}^{+}\right), 107,79,53$ \\
\hline 36.8 & 2-6-dimethoxyphenol (Syringol) & $154\left(\mathrm{M}^{+}\right), 139,96,65,51$ \\
\hline 40.27 & Hydroxymethylfurfural & $126,97\left(\mathrm{M}^{+}\right), 81,69,53$ \\
\hline 47.21 & 2-methoxy- 3-methyl hydroxy quinone & $154\left(\mathrm{M}^{+}\right), 139,93,68,65$ \\
\hline 49.81 & Vanillin & $152,151\left(\mathrm{M}^{+}\right), 123,109,81$ \\
\hline 51.5 & $\begin{array}{c}\text { 4-hydroxy-3,5-dimethoxybenzaldehyde } \\
\text { (syringyl aldehyde) }\end{array}$ & $182\left(\mathrm{M}^{+}\right), 181,111,93,65$ \\
\hline 56.25 & $\begin{array}{c}\text { 7-acetyl-2,3,4,5,6,7-hexahydrobenzofuran-4- } \\
\text { one }\end{array}$ & $180,138,137\left(\mathrm{M}^{+}\right), 122,94$ \\
\hline 67.0 & 1,2-diphenyl propan-2-one & $210,192\left(\mathrm{M}^{+}\right), 168,167,123$ \\
\hline 79.59 & $\begin{array}{c}2 \text { 2'-methylenebis 6-(1 1-dimethylethyl)-4- } \\
\text { methyl-phenol }\end{array}$ & $340,284,177\left(\mathrm{M}^{+}\right), 161,149$ \\
\hline
\end{tabular}

Table 3. Water-soluble phenolic contents and polysaccharide distrubution of kenaf hydrolysates

\begin{tabular}{lcc}
\hline Solvents & Phenolic content ( mg/L) & Polysaccharides Mp, Da \\
\hline Water & 1431.1 & $6975 ; 25$ \\
\hline Water+ 3\% THF & 3213.1 & $6075 ; 3332$ \\
\hline Water+ 3\% Methanol & 3415.3 & $68477 ; 22390 ; 24$ \\
\hline Water+ 3\% Acetone & 3562.8 & $58519 ; 19705 ; 25$ \\
\hline Water+ 3\% omp-Xylene & 3601.1 & $70496 ; 23116 ; 23$ \\
\hline
\end{tabular}

The results showed that organic solvents affect the hydrolysis and molecular mass distribution of the polysaccharides in the hydrolysates. Kenaf biomass had three fractions of polysaccharides after hydrolysis (Table 3 ). These fractions are also associated with phenolic fragments in the biomass. Type of the organic solvent used in hydrolysis process was the main factor on the differences of polysaccharides distributions (Table 3).

\section{Characterization of kenaf samples after hydrolysis}

Chemical changes that occured in the structure of kenaf biomass were determined by taking FTIR spectra of the samples before and after 
hydrolysis. Kenaf biomass spectra before and after treatments were given in Figure 2 . The $3340-3350 \mathrm{~cm}^{-1}$ in the original kenaf infrared spectrum was assigned to $\mathrm{O}-\mathrm{H}$ vibrations. This band belongs to hydroxyl groups located together by hydrogen bonds between the repeating units in the cellulose matrix. The band between 2890-
$2920 \mathrm{~cm}^{-1}$ belongs to the $\mathrm{C}-\mathrm{H}$ stretching. The $1742 \mathrm{~cm}^{-1}$ band is due to stretching of the carbonyl group in the hemicellulose structures (24). The functional group $\mathrm{C}=\mathrm{O}$ was observed at $1600-1650 \mathrm{~cm}^{-1}$. This band takes place in the lower region of $1700 \mathrm{~cm}^{-1}$ because of water absorption in the structure $(25,26)$.

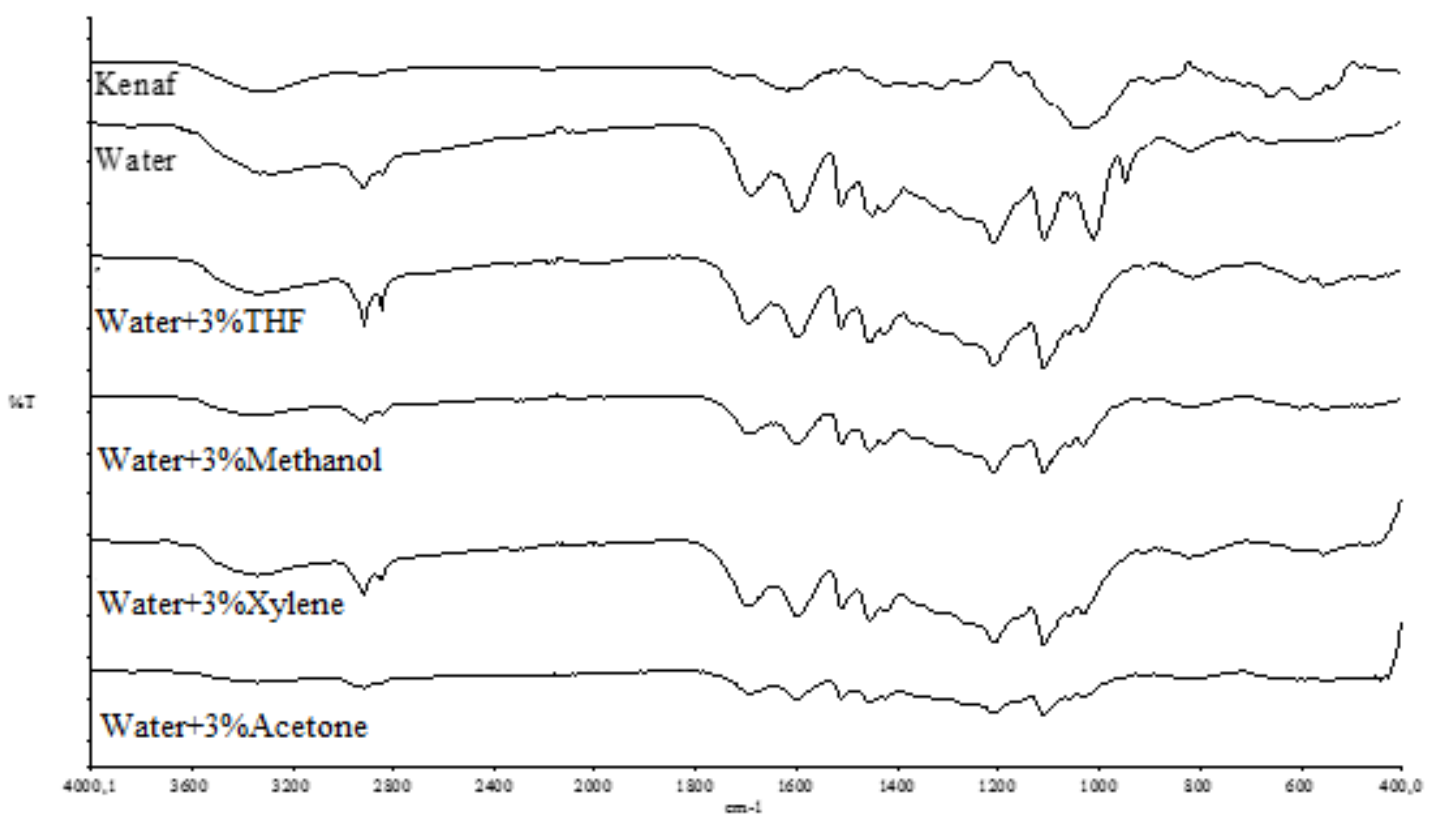

Figure 2. FTIR spectra of kenaf after hydrolysis with different water- organic solvent mixtures.

The weak bands seen around $1500-1514 \mathrm{~cm}^{-1}$ belong to lignin $(25,26)$. The $\mathrm{C}-\mathrm{H}$ vibrations in the cellulose at $1429 \mathrm{~cm}^{-1}$ and C-O-C antisymmetric vibration in glycosidic band at $1161 \mathrm{~cm}^{-1}$ were observed. The $1370 \mathrm{~cm}^{-1}$ is assigned to stretching of $\mathrm{C}-\mathrm{H}$ peaks in cellulose (26). The band at $1160-$ $1000 \mathrm{~cm}^{-1}$ is due to the $\mathrm{C}-\mathrm{O}$ vibrations. The bands that belong to typical xylan hemicellulose structures were observed between 1175 and $1000 \mathrm{~cm}^{-1}(25,26)$. The weak band around 1109 $\mathrm{cm}^{-1}$ indicates stress of glucose ring in cellulose and the presence of a band at $890 \mathrm{~cm}^{-1}$ in original kenaf attributed to $\beta$-glycosidic bonds in the cellulose structure $(27,28)$.

The band at $1742 \mathrm{~cm}^{-1}$ in the original kenaf sample disappeared after hydrolysis since acetyl, uronic, and ferulic ester bonds in hemicellulose fraction were completely broken (Figure 2). The cleavages of ester bonds caused releases of phenolic compounds $(27,26)$. The guaiacyl aromatic $\mathrm{C}-\mathrm{O}$ band stretchings in lignin structure could be seen at $1510 \mathrm{~cm}^{-1}$ (29). These bands became prominent in the non-hydrolyzed kenaf treated with any solvents. The $1460 \mathrm{~cm}^{-1}$ and $1320 \mathrm{~cm}^{-1}$ show absorption bands of syringyl ring in lignin structure (29-30). The morphological changes in kenaf samples after hydrolysis were also examined by taking SEM images (Figure 3 ). The original kenaf structure was straight and it consisted of thin fibrils. The SEM image of nonhydrolyzed kenaf indicated that dense and compact outer surface were reduced by treatments. The formations of a number of pores having a few micrometer diameters were observed after hydrolysis process with solvents (Figure 3). Substantial degradation with increasing number of pores in the rigid structure of kenaf increased after hydrolysis with ompxylene, acetone and methanol. THF hydrolysis resulted in more degradation in the kenaf structure. The cell wall structure was completely fragmented after hydrolysis in xylene. Some droplets which are known to be lignin based fragments released after lignin degradation were observed as a result of hydrolysis of the lignocellulosic material (33-35). 

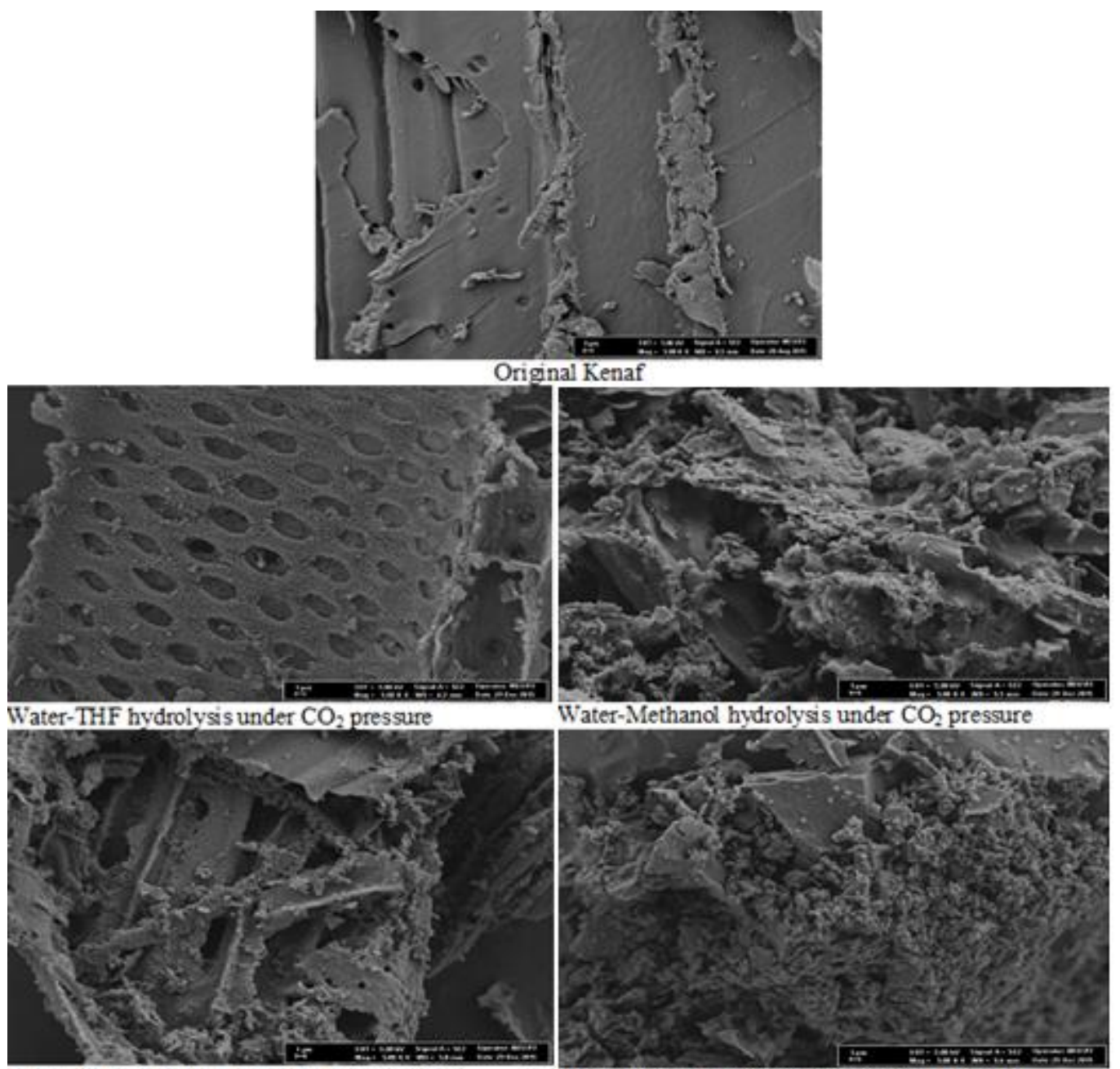

Water-Methanol hydrolysis under $\mathrm{CO}_{2}$ pressure

Water-Xylene hydrolysis under $\mathrm{CO}_{2}$ pressure

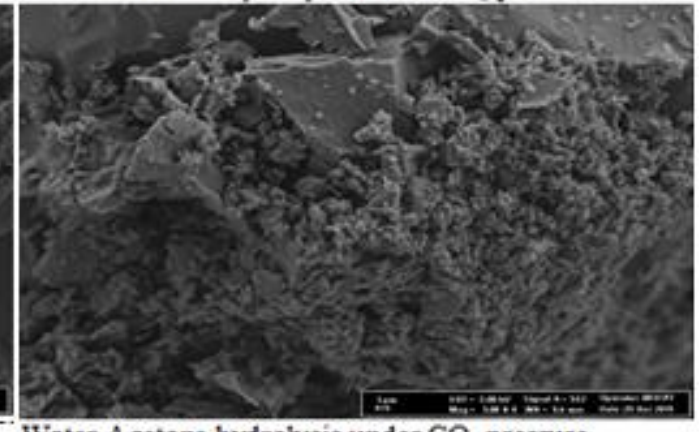

Water-Acetone hydrolysis under $\mathrm{CO}_{2}$ pressure

Figure 3. SEM images of kenaf samples after hydrolysis in different water- organic solvent mixture.

\section{CONCLUSION}

Use of organic solvents in the subcritical water hydrolysis process increased the dissolution of kenaf biomass. However, product distribution in the hydrolysates did not considerably change. Non-polar (omp-xylene) and aprotic polar (THF, acetone) solvents enhanced the hydrolysis more than polar protic (methanol) solvent. The hydrolysis process with organic solvents generated soluble polysaccharides which could be utilized for production of various value-added products including biofuels and bioproducts by thermochemical and biochemical conversion processes.

\section{ACKNOWLEDGMENTS}

Financial supports from Scientific and Technical Research Council of Turkey (TUBITAK) and Çukurova University is gratefully acknowledged (The project numbers: MAG $114 \mathrm{M} 146$ and FUK2015-4370, respectively).

\section{REFERENCES}

1. Hasyierah Noor MS, Zulkali MMD, Syahidah Ku KI. Ferulic acid from lignocellulosic biomass:
Review. Malaysian Universities Conferences on Engineering and Techonology March 8-10, 2008, Putra Brasmana, Perlis, Malaysia.

2. Saha BC. Hemicellulose bioconversion. J Ind Microbiol Biotechnol. 2003; 30:279 - 91.

3. Meryemoglu B, Hesenov A, Irmak S, Atanur OM and Erbatur $O$. Aqueous-phase reforming of biomass using various types of supported precious metal and raney-nickel catalysts for hydrogen production. Int.J. Hydrogen Energy 2010;35:12580-7.

4. Meryemoglu B, Hasanoglu A, Kaya B, Irmak S, Erbatur $O$. Hydrogen production from aqueousphase reforming of sorghum biomass: An application of the response surface methodology. Renew Energ. 2014;(62):535-41.

5. Shuai L, Yang Q, Zhu JY, Lu FC, Weimer PJ, Ralph J, Pan XJ. Comparative study of SPORL and dilute-acid pretreatments of spruce for cellulosic ethanol production. Bioresour. Technol. 2010;(101):3106-14.

6. Xin $D$, Yang $Z$, Liu $F, X u ~ X$, Zhang J. Comparison of aqueous ammonia and dilute acid 
pretreatment of bamboo fractions: structure properties and enzymatic hydrolysis. Bioresour. Technol. 2015;(175):529-36.

7. Li C, Knierim B, Manisseri C, Arora R, Scheller HV, Auer M, Vogel KP, Simmons BA, Singh S. Comparison of dilute acid and ionic liquid pretreatment of switchgrass: Biomass recalcitrance, delignification and enzymatic saccharification. Bioresour. Technol. 2010;101:4900 - 6 .

8. Kootstra AMJ, Beeftink HH, Scott EL, Sanders JPM. Comparison of dilute mineral and organic acid pretreatment for enzymatic hydrolysis of wheat straw. Biochem. Eng. J. 2009;46:126-31.

9. Hsu TC, Guo GL, Chen WH, Hwang WS. Effect of dilute acid pretreatment of rice straw on structural properties and enzymatic hydrolysis. Bioresour. Technol. 2010;101:4907-13.

10. Yan L, Zhang L, Yang B. Enhancement of total sugar and lignin yields through dissolution of poplar wood by hot water and dilute acid flowthrough pretreatment. Biotechnol. Biofuels. 2014;7:76.

11. Akpinar O, Levent O, Sabanci S, Uysal RS, Sapci B. Optimization and comparison of dilute acid pretreatment of selected agricultural residues for recovery of xylose. Bio Resources 2011;6:4103-16.

12. Caboni $E$, Tonelli MG, Lauri $P$, Iacovacci $P$, Kevers C, Damiano C, Gaspar T. Biochemical aspects of almond microcuttings related to in vitro rooting ability. Biologia Plant. 1997; 39: 91-7.

13. $\mathrm{Ni} \mathrm{Y}$, and $\mathrm{Hu} \mathrm{Q}$. Alcell Lignin Solubility in Ethanol-Water Mixtures. Journal of Applied Polymer Science. 1995;57:1441-6.

14. Wang Q, Chen K, Li J, Yang G, Liu S, Xu J. The solubility of lignin from bagasse in a 1,4butanediol/water

BioResources.2011;6;3034-43.

15. Boeriu CG, Fiţigău FI, Gosselink RJA, Frissen $A E$, Stoutjesdijk J, Peter F. Fractionation of five technical lignins by selective extraction in green solvents and characterisation of isolated fractions. Ind Crops Prod. 2014;62:481-90.

16. Ye $Y$, Liu $Y$, and Chang J. Application of solubility parameter theory to organosolv extraction of lignin from enzymatically hydrolyzed cornstalks. BioRes. 2014;9:3417-27.

17. Reichardt C, Welton T. Solvents and Solvent Effects in Organic Chemistry, Wiley-VCH, Weinheim, 2006.

18. Maurel P. Relevance of Dielectric Constant and Solvent Hydrophobicity to the Organic
Solvent Effect in Enzymology J. Biol. Chem. 1978;253:1677-83.

19. Mariella RP, Raube RR, Budde J, Moore CE. The effect of the dielectric constant of the solvent on the ultraviolet absorption spectra of some nonaromatic ketones J. Org. Chem. 1954; 19: 67882.

20. Sun RC, Sun XF, Ma XH. Effect of ultrasound on the structural and physicochemical properties of organosolv soluble hemicelluloses from wheat straw. Ultrasonics Sonochemistry. 2002; 9: 95101.

21. Sun RC, Tomkınson J. Separation and Characterization of Cellulose from Wheat Straw. Separation Science and Technology. 2004;39: 391-411.

22. Buranov AU, Mazza G. Extraction and characterization of hemicelluloses from flax shives by different methods. Carbohydrate Polymers. 2010;79: 17-25.

23. Corredor DY. Pretreatment and enzymatic hydrolysis of lignocellulosic biomass. PhD dissertation. Department of Biological and Agricultural Engineering, Kansas State University, Manhattan, Kansas, 2008.

24. Espinoza-Acosta JL, Torres-Chávez PI, Carvajal-Millán E, Ramírez-Wong $B$, Bello-Pérez LA, Montaño-Leyva B. Ionic liquids and organic solvents for recovering lignin from lignocellulosic biomass. BioResources. 2014; 9:3660-87.

25. Araque E, Parra C, Freer J, Contreras D, Rodríguez J, Mendonça R, Baeza J. Evaluation of organosolv pretreatment for the conversion of Pinus radiata D. Don to ethanol. Enzyme Microb. Technol. 2008; 43:214-9.

26. Ghozatloo A, Mohammadi-Rovshandeh J, Hashemi S. Optimization of pulp properties by dimethyl formamide pulping of rice straw. Cellul. Chem. Technol. 2006;40:659-67.

27. Zhao X, Cheng K, Liu D. Organosolv pretreatment of lignocellulosic biomass for enzymatic hydrolysis. Appl. Microbiol. Biotechnol. 2009;82:815-27.

28. Sun R, Lawther JM, Banks WB. Fractional and structural characterization of wheat straw hemicelluloses. Carbohydrrate Polymers. 1999;49:415-23.

29. Sene CFB, Mccan MC, Wilson RH and Grinter R. Fourier-transform Raman and Fouriertransform infrared spectroscopy. An investigation of five higher plant cell walls and their components. Plant Physiology. 1994;106:162331.

30. Pandey KK. A study of chemical structure 
of soft- and hardwood and wood polymers by FTIR spectroscopy. J. Appl Polym Sci. 1999;71:1969-75.

31. Faix O. Fourier Transform Infrared Spectroscopy, In: Methods in Lignin Chemistry, T.E. Timell (Ed.), Springer-Verlag, Germany, 1992.

32. Sun RC, Tomkınson J. Separation and Characterization of Cellulose from Wheat Straw. Separation Science and Technology 2004;39:391-411.

33. Micic $M$, Benitez I, Ruano $M$, Mavers $M$, Jeremic M, Radotic K, Moy V, Leblanc RM. Probing the lignin nanomechanical properties and ligninlignin interactions using the atomic force microscopy. Chemical Physics Letters. 2001;347:41-5.

34. Donohoe BS, Decker SR, Tucker MP, Himmel ME, Vinzant TB. Visualizing Lignin Coalescence and Migration Through Maize Cell Walls Following Thermochemical Pretreatment. Biotechnology and Bioengineering. 2008;101:913-25.

35. Selig MJ, Viamajala S, Decker SR, Tucker MP, Himmel MP, Vinzant TB. Deposition of Lignin Droplets Produced During Dilute Acid Pretreatment of Maize Stems Retards Enzymatic Hydrolysis of Cellulose, Biotechnology Progress. 2007;23:1333-9. 